may have occurred if they sought testing outside our healthcare system.

Healthcare facilities continue to experience challenges with medical supply chains. N95 respirators should be prioritized for HCWs involved in AGPs on patients with proven or suspected COVID-19. Shifting ambulatory testing to outdoor areas and parking garages allows for natural airflow and ventilation, decreases indoor crowding, and thus can decrease the risk of viral transmission to individuals, including HCWs. ${ }^{4}$ To preserve PPE supplies while balancing HCW safety, regulatory bodies should allow healthcare facilities to determine the appropriate PPE for their employees, based on $\mathrm{HCW}$-focused risk assessments, overall community disease prevalence, patient testing location (indoors versus outdoors), and length of anticipated close contact. Our experience demonstrates that NP and OP specimen collection can be safely performed without use of N95 respirators as part of HCW PPE.

Acknowledgments. The authors would like to thank Debbie Lamberger, Melissa Preciso-Temple, and Andrew Christenson for their assistance with the preparation of this manuscript.
Conflicts of interest. All authors report no conflicts of interest relevant to this article.

\section{References}

1. Interim infection prevention and control recommendations for healthcare personnel during the coronavirus disease 2019 (COVID-19) Pandemic. Centers for Disease Control and Prevention website. https://www.cdc.gov/ coronavirus/2019-ncov/hcp/infection-control-recommendations.html. Published 2020. Accessed November 21, 2020.

2. Davitkov P, Anderson DJ, Bhimraj A, et al. Infectious Disease Society of America guidelines on infection prevention for health care personnel caring for patients with suspected or known COVID-19. Clin Infect Dis 2020. doi: 10.1093/cid/ciaa1063.

3. Clinical care, and healthcare infection prevention and control guidance for COVID-19. Oregon Health Authority website. https://sharedsystems. dhsoha.state.or.us/DHSForms/Served/le2288J.pdf. Published 2020. Accessed November 21, 2020.

4. Weiss EA, Ngo A, Gilbert GH, Quinn, JV. Drive-through medicine: a novel proposal for rapid evaluation of patients during an influenza pandemic. Ann Emerg Med 2010:55:268-273.

\title{
Donning and doffing technique for coverall personal protective equipment, is it safe?
}

\author{
Dayana Souza Fram PhD (1), Wanderson Eduardo Gomes de Souza Coelho RN (1), Luciana de Oliveira Matias MSc (10, \\ Daniela Vieira da Silva Escudero MSc (1), Thaysa Sobral Antonelli MD (1), Diogo Boldim Ferreira MSc (1) and \\ Eduardo Alexandrino Medeiros PhD (1) \\ Division of Infection Control and Hospital Epidemiology, Hospital São Paulo, Universidade Federal de São Paulo, São Paulo, SP, Brazil
}

To the Editor-The sudden spread of coronavirus disease 2019 (COVID-19) increased the demand for personal protective equipment (PPE), resulting in shortages. ${ }^{1,2}$ An observational compliance study regarding specific precautions for COVID-19 patients showed that among improper PPE use, 193 of 322 (60.\%) were classified as wasteful practices that contributed to the shortage of these products. $^{3}$

The lack of gowns has ignited a search for alternative PPE such as coveralls. The World Health Organization (WHO) guideline did not recommend coveralls as alternative PPE. ${ }^{2}$ The Centers for Disease Control and Prevention mentioned coveralls as alternative PPE, but it did not recommend standardized donning and doffing techniques in the context of COVID-19. ${ }^{4}$

In this study, in a simulated healthcare environment, we proposed replacing the standard gown by a coverall PPE for healthcare professionals (HCPs) providing assistance to patients suspected or confirmed of COVID-19. We tested the safety of donning and doffing the coverall PPE, and we evaluated the opinions of HCPs regarding its

Author for correspondence: Dayana Souza Fram, E-mail: dayana.fram@unifesp.br Cite this article: Fram DS, et al. (2022). Donning and doffing technique for coverall personal protective equipment, is it safe?. Infection Control \& Hospital Epidemiology, 43: 413-415, https://doi.org/10.1017/ice.2020.1429 use. This donning and doffing technique was based on and adapted from WHO PPE guidelines on filovirus disease outbreak response. ${ }^{5}$

This experimental study was conducted from July to September 2020 in a Brazilian public university. Researchers produced a video and an educational poster based on the technique proposed. The donning sequence was divided into 8 steps, and the doffing sequence was divided into 12 steps (Supplementary Material online).

The study population consisted HCPs in a teaching hospital who assisted patients suspected or confirmed of COVID-19 and consented to volunteer in the study. Overall, 12 professionals were included in the study: 4 were nurses, 4 were physiotherapists, and 4 were physicians. The tests were simulated at the Skills and Simulation Center of the Federal University of São Paulo, Brazil, on 6 different days.

The HCPs were instructed to wear a scrub suit and to watch the video produced to this study. Nurses simulated intimate hygiene and patient positioning; physiotherapists simulated bag squeezing and early mobilization; and physicians simulated cardiac massage and orotracheal intubation.

Before each experiment, a fluorescent marker was applied to the simulation dummy and bed surfaces. A poster showing the sequence of donning and doffing the PPE was placed on the wall of the simulation room. 
Table 1. HCPs Contaminated Sites After Patient Care Tasks Simulation and After Removal of PPE

\begin{tabular}{|c|c|c|c|c|c|c|c|c|c|c|c|c|c|c|c|c|}
\hline \multirow[b]{3}{*}{ Sites } & \multicolumn{8}{|c|}{$\begin{array}{l}\text { HCPs Contaminated Sites After Patient Care Tasks } \\
\text { (Before Removal of PPE) }\end{array}$} & \multicolumn{8}{|c|}{ HCPs Sites Contaminated After Removal of PPE } \\
\hline & \multicolumn{2}{|c|}{$\begin{array}{l}\text { Nurses } \\
(\mathrm{N}=4)\end{array}$} & \multicolumn{2}{|c|}{$\begin{array}{l}\text { Physiothera- } \\
\text { pists }(N=4)\end{array}$} & \multicolumn{2}{|c|}{$\begin{array}{l}\text { Physicians } \\
\text { (N=4) }\end{array}$} & \multicolumn{2}{|c|}{$\begin{array}{l}\text { Total HCPs } \\
(\mathrm{N}=12)\end{array}$} & \multicolumn{2}{|c|}{$\begin{array}{l}\text { Nurses } \\
(\mathrm{N}=4)\end{array}$} & \multicolumn{2}{|c|}{$\begin{array}{l}\text { Physiothe- } \\
\text { rapists } \\
(\mathrm{N}=4)\end{array}$} & \multicolumn{2}{|c|}{$\begin{array}{l}\text { Physicians } \\
\text { (N=4) }\end{array}$} & \multicolumn{2}{|c|}{$\begin{array}{l}\text { Total HCPs } \\
(\mathrm{N}=12)\end{array}$} \\
\hline & No. & $\%$ & No. & $\%$ & No. & $\%$ & No. & $\%$ & No. & $\%$ & No. & $\%$ & No. & $\%$ & No. & $\%$ \\
\hline Head & 0 & 0 & 0 & 0 & $4^{b}$ & 100 & 4 & 33.3 & 0 & 0 & 0 & 0 & 0 & 0 & 0 & 0 \\
\hline Chest & 4 & 100 & 4 & 100 & 4 & 100 & 12 & 100 & 0 & 0 & 0 & 0 & 0 & 0 & 0 & 0 \\
\hline Abdomen & 4 & 100 & 4 & 100 & 3 & 75 & 11 & 91.7 & 0 & 0 & 0 & 0 & 0 & 0 & 0 & 0 \\
\hline Pelvis & 4 & 100 & 4 & 100 & 3 & 75 & 11 & 91.7 & 0 & 0 & 0 & 0 & 0 & 0 & 0 & 0 \\
\hline Upper limbs & 4 & 100 & 4 & 100 & 2 & 50 & 10 & 83.3 & 0 & 0 & 0 & 0 & 0 & 0 & 0 & 0 \\
\hline Hands & 4 & 100 & 4 & 100 & 4 & 100 & 12 & 100 & $1^{\mathrm{d}}$ & 25 & 0 & 0 & 0 & 0 & 1 & 8.3 \\
\hline
\end{tabular}

Notes: PPE, personal protective equipment; HCPs, healthcare professionals.

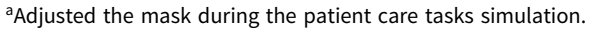

${ }^{\mathrm{b}}$ Contamination during the pulmonary auscultation.

CHCPs touched their backs after simulated patient care tasks.

${ }^{\mathrm{d} C o n t a m i n a t i o n}$ should be avoided with proper hand hygiene after removal of PPE.

${ }^{\mathrm{e}} \mathrm{HCP}$ touched a lower limb during PPE removal.

The contaminated sites were assessed using ultraviolet light after patient care and removal of PPE, and each spot of contamination was recorded on a specific form. Additionally, all professionals were photographed and filmed during the following actions: donning the PPE, during the procedure, after the procedure, doffing the PPE, and after doffing the PPE. After the experiment, all HCPs filled out a form about the donning and doffing technique and their personal opinion of the coverall PPE. The data obtained from the forms completed by the researchers were validated by the videos and photos. A descriptive analysis was conducted.

Researchers identified 9 contaminated sites after patient care tasks. Some of the spots were common to almost all HCPs, such as the chest and hands (100\%), abdomen and pelvis (11 of $12,91.7 \%$ ), and upper limbs (10 of 12, 83.3\%). Some sites varied according to the HCP category and the care tasks simulated.

After the removal of PPE, the analysis showed that only 2 HCPs (16.7\%) self-contaminated: a hand and a lower limb. The body surface contamination by both HCPs was $11 \%$ (1 of 9 sites), which could have been prevented by proper hand hygiene and compliance with the doffing technique (Table 1). Of the 12 HCPs included in the study, 7 HCPs (58.3\%) reported difficulty with donning the coverall PPE, specifically during step 3 , and $100 \%$ reported difficulty doffing the PPE, specifically from the steps 4 to 7 . Furthermore, 4 HCPs (33\%) found the PPE uncomfortable, but $11(91.7 \%)$ rated it safe.

In the present study, we showed that the contamination sites before removal of PPE were task dependent and varied among the HCP categories. In a Cochrane review, studies included in evaluating PPE donning and doffing techniques proceeded with the direct contamination of PPE and evaluated only the postdoffing contamination. ${ }^{6}$ A study by Chughtai et $\mathrm{al}^{7}$ described the risk of self-contamination associated with the doffing of PPE compared 10 protocols recommended for Ebola, showed 13\% contamination and, when coveralls were included, the contamination rate was $16.7 \%$. In our study, we found $16.7 \%$ contamination, the same rate described by Chughtai et al.

Chen et $\mathrm{al}^{8}$ performed a simulation study that evaluated the contamination of 46 frontline nonmedical staff after doffing PPE for COVID-19 (including a coverall). They found that $45.7 \%$ of HCPs contaminated their upper chest, $43.5 \%$ contaminated their hands, 32.6\% contaminated their chest, $13 \% \%$ contaminated their upper limbs, and $10.9 \%$ contaminated their lower limbs. However, these researchers did not describe the donning and doffing technique used. ${ }^{8}$ Our results showed $8.3 \%$ contamination on the hands and lower limbs.

The body surface contamination rate in the present study was $11 \%$, showing a low risk. We did not find other studies that analyzed these specific data. Chughtai et $\mathrm{al}^{7}$ evaluated user satisfaction in wearing coveralls, and $20 \%$ of HCP reported difficulty in donning PPE and 23\% reported difficulty in doffing PPE. ${ }^{7}$ In our study, $58.3 \%$ reported difficulty in donning, $100 \%$ reported difficulty in doffing, and $91.7 \%$ felt safe in their PPE.

Despite the low risk of contamination with this proposed technique, we believe that coverall PPE should not be recommended as a standard for COVID-19 patient assistance, due to the difficulty reported in handling it. However, coveralls can be employed as an alternative to gowns during periods of shortage, like those we have faced during the COVID-19 pandemic, as long as HCPs follow a safe donning and doffing protocols.

Supplementary material. To view supplementary material for this article, please visit https://doi.org/10.1017/ice.2020.1429

Acknowledgments. We thank the Skills and Simulation Center of the Federal University of São Paulo, the Recommed Company, the healthcare professionals who volunteered in the study, and the following: Isabel Cristina Meleiro Westin, Luiz Aralan Leite and Patricia Nicolini.

Financial support. No relevant financial support was provided to this article. 
Conflicts of interest. All authors report no conflicts of interest relevant to this article.

\section{References}

1. Ranney ML, Griffeth V, Jha AK. Critical supply shortages--the need for ventilators and personal protective equipment during the COVID-19 pandemic. N Engl J Med 2020;382:e41.

2. Rational use of personal protective equipment for coronavirus disease (COVID-19) and considerations during severe shortages: interim guidance, 06 April 2020. Word Health Organization website. https:/apps.who.int/iris/ handle/10665/331695. Published 2020. Accessed November 10, 2020.

3. Fram DS, Escudero DVS, Matias LO, et al. Personal protective equipment: shortage or waste? Infect Control Hosp Epidemiol 2020. doi: 10.1017/ice.2020.354.

4. Optimizing personal protective equipment (PPE) supplies, 16 July, 2020. Centers for Disease Control and Prevention website. https://www.cdc.gov/ coronavirus/2019-ncov/hcp/ppe-strategy/index.html. Published 2020. Accessed November 10, 2020.

5. Personal protective equipment in the context of filovirus disease outbreak response-rapid advice guideline. World Health Organization website. http:// www.who.int/csr/resources/publications/ebola/ppe-guideline/en/. Published 2014. Accessed November 10, 2020.

6. Verbeek JH, Rajamaki B, Ijaz S, et al. Personal protective equipment for preventing highly infectious diseases due to exposure to contaminated body fluids in healthcare staff. Cochrane Database Syst Rev 2020;4(4): CD011621.

7. Chughtai AA, Chen X, Macintyre CR. Risk of self-contamination during doffing of personal protective equipment. Am J Infect Control 2018;46:1329-1334.

8. Chen B, Jin H, Yang R. Application of fluorescence method in the process of personal protective equipment removal. Am J Infect Control 2020;48:857-858.

\title{
The 501.V2 and B.1.1.7 variants of coronavirus disease 2019 (COVID-19): A new time-bomb in the making?
}

\author{
Taha Bin Arif MBBS \\ Department of Medicine, Dow Medical College, Dow University of Health Sciences, Karachi, Pakistan
}

To the Editor-The second wave of coronavirus disease 2019 (COVID-19) has been incessantly causing catastrophe across the world. According to the World Health Organization (WHO), the total numbers of confirmed cases and deaths as of December 20, 2020, were 75,110,651 and 1,680,395, respectively. ${ }^{1}$ America is leading, with the highest number of cases, followed by Europe, Southeast Asia, the Eastern Mediterranean, Africa, and the Western Pacific. Although many countries have loosened lockdowns and travel restrictions, the crisis is not yet over. Many emerging economies were already facing feeble growth before the crisis; the COVID-19 shock introduced difficult obstacles and devastated these economies. ${ }^{2}$ This plight has highlighted the need for immediate action to cushion the pandemic's health and economic repercussions, protect susceptible populations, and set the stage for a lasting recovery. ${ }^{2}$

Apparently, severe acute respiratory coronavirus virus 2 (SARS-CoV-2) brings a new challenge to the world with every new day. Genomic scientists in South Africa noticed a particular variant of SARS-CoV-2 in the samples collected over the past 2 months and named it the 501.V2 variant. ${ }^{3}$ The distinguishing feature of this variant is that it has several mutations in the parts that allow it to attach to human cells, which is a target of antibody therapies and vaccines. Preliminary analysis of the swabs revealed faster spread associated with high viral load. One of the mutations is N501Y, which occurs in the genetic sequence that codes for viral spike protein that binds to the human ACE-2 receptor. ${ }^{4}$ This mutation is most likely associated with a faster spread in other countries like Britain and Australia. ${ }^{3}$ The 3 leading vaccines are producing

Author for correspondence: Taha Bin Arif, E-mail: tahaarif20@yahoo.com

Cite this article: Arif TB. (2022). The 501.V2 and B.1.1.7 variants of coronavirus disease 2019 (COVID-19): A new time-bomb in the making?. Infection Control of Hospital Epidemiology, 43: 415-416, https://doi.org/10.1017/ice.2020.1434 antibodies against many regions of the spike protein. It has been predicted that a single mutation in the spike protein will not cause the failure of the vaccine. England's Health Secretary Matt Hancock said, "If this new viral strain causes vaccine failure or reinfection, then that case would be treated as a high priority for genetic sequencing." 4

Another variant, B.1.1.7, was detected by the evolution working group of the World Health Organization (WHO) with UK medical authorities. This strain has been detected in the Netherlands, Denmark, and Australia, and it is predicted to affect the pandemic. ${ }^{5}$ Two major concerns related to this variant are the unprecedented number of mutations and the speed of spread. Scientists say that 23 letters in the viral genetic code have been changed, of which 17 might cause behavioral changes in the entry into and propagation of human cells. Computer modeling of this strain suggests that it is $70 \%$ more transmissible than other SARS-CoV-2 strains. These characteristics enable this new strain to supplant other strains of SARS$\mathrm{CoV}-2$. However, there is uncertainty regarding the course of illness, the severity of disease in the people infected with B.1.1.7 strain, and the effectiveness of vaccines under development against it. ${ }^{5}$

These new mutant strains are presenting a new global threat in the COVID-19 pandemic. By December 9, 2020, the 501.V2 strain occupied $62 \%$ of London, $59 \%$ of eastern England, and $43 \%$ of the southeastern region of the England. ${ }^{6}$ Due to fear of this new COVID-19 strain, countries like Italy, Belgium, France, and the Netherlands have banned flights to and from the United Kingdom. Saudi Arabia has also suspended its international commercial flights recently. This ban has also been applied to the passengers coming through land and seaport, but it has not been applied to the imports, commodities, and supply chains from countries where the mutated virus has not appeared. $^{6}$ 